\title{
Aturan Asosiasi Antar Item Terjual pada Data Penjualan Minimarket Milik Komunitas di Hari Besar Tertentu Menggunakan Algoritma Apriori
}

\author{
Luky Fabrianto $^{1}$, Novianti Madhona Faizah ${ }^{2}$, Johan Hendri Prasetyo ${ }^{1}$, Bobby Suryo Prakoso ${ }^{1}$, \\ Gani Wiharso ${ }^{1}$ \\ ${ }^{1}$ Universitas Nusa Mandiri \\ Program Studi Bisnis Digital \\ Jl. Raya Jatiwaringin No.2, 13620, Jakarta, Indonesia \\ E-mail: luky.lfb@nusamandiri.ac.id \\ ${ }^{2}$ Universitas Tama Jagakarsa \\ Program Studi Sistem Informasi \\ Jl. TB Simatupang No.152, Kota Jakarta Selatan, Daerah Khusus Ibukota Jakarta 12530 \\ E-mail: novianti@jagakarsa.ac.id
}

\begin{abstract}
Abstrak
Salah satu metode data mining yang cukup popular untuk mendapatkan hubungan antar sebuah item dengan item tertentu adalah metode aturan asosiasi dengan menggunakan algoritma APriori, metode ini cukup tepat untuk menghasilkan pola aturan hubungan antar jenis item yang terjual berdasarkan data penjualan. Nilai support pada frequent item dan confidence pada rules yang didapat bisa memberikan wawasan yang dapat ditindaklanjuti oleh pengelola minimarket, koperasi dan lain sebagainya. Pengkategorian jenis produk pada minimarket cukup banyak sementara jumlah keseluruhan transaksi dalam satu tahun juga sangat banyak, sedangkan jumlah jenis item terjual dalam suatu transaksi sangat sedikit, dengan demikian nilai threshold tidak bisa terlampau tinggi. Pada penelitian ini metode aturan asosiasi dilakukan per event atau periode tertentu yang berkaitan dengan hari besar umat Islam, didapatkan rule tertinggi yaitu makanan ringan $=>$ sembako dengan confidence sebesar $46 \%$ dan support sebesar $16 \%$ yang terjadi pada bulan Ramadhan.
\end{abstract}

Kata kunci: Data mining, Aturan Asosiasi, Support, Confidence, Rule, Frequent item

\begin{abstract}
The popular data mining methods to find the relationship between an item and another item is the association rule method using Apriori algorithm, this method is precise to generate a pattern of relationship rules between the types of items sold based on sales data. Support values on frequent items and confidence in the rules obtained can be an actionable insight that can be follow up by minimarket managers, cooperatives, etc. The categorization of product types in minimarkets is much while the total number of transactions in a year is also large, but the number of types of items sold in a transaction is very few, thus the threshold value cannot be high. In this study, association rule method was carried out per event or certain period related to Muslim holidays, highest rule was obtained is Makanan ringan => Sembako with $46 \%$ confidence and $16 \%$ support in the month of Ramadan.
\end{abstract}

Keywords: Data mining, Association Rule Mining, Support, Confidence, Rule, Frequent item 


\section{Pendahuluan}

Toko modern dari prespektif teknologi minimalnya adalah pemanfaatan komputerisasi untuk perhitungan dan penyimpanan segala transaksi keuangan yang terjadi. Pemanfaatan teknologi informasi juga sangat membantu para pelaku usaha dalam banyak hal, seperti: kondisi stok barang, pencatatan transaksi penjualan, pemesanan barang ke supplier, dan lain sebagainya.

Banyak hal menarik dalam analisis penjualan dan seperti tidak ada habisnya pembahasan tentang hal tersebut, semisal dari sisi penjualan, diskon, kebiasaan belanja customer, penyusunan rak display, hingga peramalan keuntungan. Data penjualan biasanya memiliki atribut transaksi seperti tanggal, nomor, waktu, kode produk, keterangan produk, kuantiti, harga dan sebagainya. Dari data yang ada bisa dibuatkan atribut tambahan seperti pengkategorian produk agar dapat dilakukan pengasosiasian item pada keranjang belanja.

Dalam banyak penelitian tentang analisis keranjang belanja yang paling sering digunakan adalah metode aturan asosiasi dengan tujuan agar pembeli mudah menjangkau barang-barang yang akan dibeli, memberi penawaran untuk barang terkait, penataan rak belanja serta ketika pengelola ingin melakukan kulakan atau pengisian stok barang. Penelitian ini menganalisis kebiasaan pembeli ketika ada event tertentu yang berkaitan dengan komunitasnya.

Pada penelitian ini yang dijadikan objek adalah minimarket dalam naungan koperasi yang dimiliki dan dikelola oleh komunitas muslim disekitaran Cimanggis kota Depok, oleh karena itu pada beberapa hari besar tertentu khususnya hari besar agama Islam, seperti bulan Ramadhan, Idul Fitri, Idul Adha, Maulid Nabi Muhammad SAW, dan Tahun Baru Islam yang mana komunitas tersebut sering mengadakan santunan, charity, bantuan dan kegiatan social lainnya. Penelitian ini bertujuan untuk menyiapkan ketersediaan stok barang menjelang beberapa hari besar yang dimaksud. Dari raw data yang didapat, dilakukan pemilihan atribut yang akan dijadikan model aturan asosiasi, dari atribut keterangan barang dilakukan pengkategorian jenis barang yang selanjutnya ditransformasi kedalam biner guna penerapan algoritma A Priori, tahap terakhir adalah menetapkan nilai threshold untuk mendapatkan nilai support dan confident yang optimal, dimana kedua nilai tersebut memberkan pengaruh terhadap aturan asosiasi yang dihasilkan.

\section{Tinjauan Pustaka}

Sumber daya informasi baru yang luas membuat para ilmuwan, insinyur, dan pebisnis membutuhkan teknik analisis yang efisien untuk mengekstrak pengetahuan yang berguna dan efektif mengungkap pola pengetahuan baru yang berharga (Shelke et al., 2017). Saat ini toko konvensional yang dioperasikan secara manual menganggap perlu untuk berubah menjadi toko modern dengan mamanfaatkan teknologi informasi (Edward et al., 2019). Makalah (Aishwarya, 2016) membahas aturan asosiasi untuk pengetahuan ekstraksi data mining dari database dan tata letak toko supermarket baru berdasarkan asosiasi antar kategori. Pendekatan ini memungkinkan supermarket untuk mengelompokkan produk di sekitar peluang pembelian yang bermakna terkait dengan penggunaan aturan asosiasi. Dalam makalahnya (Kaur \& Kang, 2016) membahas teknik data mining yaitu association rule mining dan menyediakan algoritma baru yang dapat membantu untuk memeriksa perilaku pelanggan serta membantu dalam dalam hal meningkatkan penjualan. Penelitian tentang aturan asosiasi pada toko yang dimiliki komunitas dan dilakukan pada event tertentu belum kami dapatkan.

\section{Metode Penelitian}

\section{a. Ekspolrasi Data}

Dataset yang digunakan adalah data transaksi penjualan dalam periode setahun, tabel. 1 adalah keterangan atribut, untuk menjalankan metode aturan asosiasi diperlukan pemilihan atribut sesuai dengan yang dibutuhkan, pengkategorian jenis item terjual, transformasi data dan deskripsi statistic terhadap data.

TABEL 1

ATRIBUT DATA PENJUALAN (Luky, 2021)

\begin{tabular}{|c|l|l|}
\hline No & \multicolumn{1}{|c|}{ Atribut } & \multicolumn{1}{c|}{ Keterangan } \\
\hline 1 & Tanggal & Tanggal transaksi \\
\hline 2 & No transaksi & Nomor transaksi \\
\hline 3 & Anggota & Jenis keanggotaan \\
\hline 4 & Kode & Kode barang \\
\hline 5 & Ket Barang & Keterangan detail barang \\
\hline 6 & Qty & Jumlah item barang \\
\hline 7 & Harga & Harga satuan barang \\
\hline 8 & Tot Harga & Total harga item \\
\hline 9 & Distro & Distributor barang \\
& & \\
\hline
\end{tabular}




\section{b. Aturan Asosiasi}

Aturan asosiasi atau association rule mining adalah teknik untuk menemukan aturan asosiatif yaitu berupa kombinasi item tersembunyi dalam satu transaksi yang terdapat dalam dataset yang besar, sebagai contoh dalam sebuah transaksi adalah mengetahui seberapa besar kemungkinan suatu jenis item dibeli bersamaan dengan jenis item lain (Kaur \& Kang, 2016), istilah lain dari analisis asosiasi dikenal dengan Market Basket Analysis (MBA) (Wijaya, 2017). tabel 2, merupakan contoh daftar transaksi.

TABEL 2

CONTOH ATURAN ASOSIASI (Kaur \& Kang, 2016)

\begin{tabular}{|c|l|}
\hline No Trans & \multicolumn{1}{|c|}{ Item } \\
\hline 1 & Snack, Oral Hygiene, House Hold \\
\hline 2 & Personal Care, Oral Hygiene, Snack \\
\hline 3 & Snack, Personal Care \\
\hline
\end{tabular}

Relasi yang menarik dapat direpresentasikan dalam bentuk aturan asosiatif berikut:

\section{Personal Care $\rightarrow$ Snack}

Metode dasar analisis asosiasi terbagi menjadi dua tahap:

\section{Analisa pola frekuensi tinggi}

Tahap ini mencari kombinasi item yang memenuhi syarat minimum dari nilai support dalam database. Nilai support sebuah item diperoleh dengan rumus berikut:

Jumlah Transaksi mengandung A

$$
\operatorname{Support}(\mathrm{A})=\frac{\text { Total Transaksi }}{\text { Tol }}
$$

Sedangkan nilai support dari 2 item diperoleh dari rumus berikut:

Support $(\mathrm{A} \cap \mathrm{B})=$

Jumlah Transaksi mengandung A dan B

Total Transaksi

\section{Pembentukan Aturan Asosiatif}

Setelah semua pola frekuensi tinggi ditemukan, barulah dicari aturan asosiatif yang memenuhi syarat minimum untuk confidence dengan menghitung confidence aturan assosiatif $\mathrm{A}=>\mathrm{B}$.
Nilai confidence dari aturan $\mathrm{A}=>\mathrm{B}$ diperoleh dari rumus berikut:

Confidence $=\mathrm{P}(\mathrm{A} \mid \mathrm{B})=$

$$
\frac{\text { Jumlah Transaksi mengandung A dan B }}{\text { Jumlah Transaksi mengandung A }}
$$

\section{c. Pengkategorian Jenis Barang}

Guna menyederhanakan Jenis barang yang sangat banyak maka perlu dilakukan kategorisasi agar mempermudah metode aturan asosiasi mendapatkan model dan model didapatkan memiliki nilai confidence yang baik. Pengkategorian mengikuti pola penempatan barang yang utarakan oleh (Sujana, 2005).

\section{Hasil Dan Pembahasan}

\section{a. Pemilihan Atribut Dan Pengkategorian Jenis Barang}

Tabel 1. merupakan isi dari dataset original, untuk menemukan pola aturan asosiasi tidak diperlukan semua atribut, hanya beberapa atribut saja yang diperlukan serta ditambahkan satu atribut yaitu Jenis Barang/item, pengelompokan jenis barang mengikuti pola penempatan barang (Sujana, 2005), tabel 3. adalah atribut yang akan dipakai untuk menemukan pola aturan asosiasi.

TABEL 3

ATRIBUT YANG DIPAKAI (Luky, 2021)

\begin{tabular}{|c|l|l|}
\hline No & \multicolumn{1}{|c|}{ Atribut } & \multicolumn{1}{c|}{ Keterangan } \\
\hline 1 & No transaksi & Nomor transaksi \\
\hline 2 & Ket Barang & Keterangan detail barang \\
\hline 3 & Qty & Jumlah item barang \\
\hline 4 & Jenis Barang & Pengelompokan jenis barang \\
\hline
\end{tabular}

Dalam pengelompokan jenis barang, setiap barang yang terjual diberikan label pengkategorian, terdapat sebelas pengkategorian, sebagai berikut:

1. Dry food dan mie adalah makanan kering atau makanan dalam kemasan yang memiliki daya tahan penyimpanan lebih lama dan biasanya memerlukan penanganan lebih lanjut untuk dikonsumsi, contohnya: mie instan, sarden, bawang goreng dan sebagainya.

2. Frozen adalah makanan beku yang disimpan dalam freezer dan biasanya memerlukan penanganan 
lebih lanjut untuk dikonsumsi, contohnya: ayam beku, es krim, yogurt dan sebagainya.

3. Makanan ringan atau snack merupakan istilah bagi makanan yang bukan merupakan menu utama, contohnya : biscuit, wafer, permen dan sebagainya.

4. AMDK merupakan kependekan dari Air Minum Dalam Kemasan yang berisi air putih jernih, dijual dalam beberapa macam ukuran kemasan, misalnya: cup atau gelas, botol 600 mililiter, 330 mililiter, 1-liter dan ukuran lainnya.

5. Minuman umumnya menunjuk kepada cairan yang bisa langsung dikonsumsi dan dikemas dalam beberapa ukuran dan rasa tertentu, contohnya: teh, kopi, susu, jus dan sebagainya.

6. Bahan minuman merupakan bahan yang dengan penanganan lanjut dapat dikonsumsi secara diminum, biasanya dikemas dalam sachet atau pouch, seperti: kopi, teh, susu, jahe dan sebagainya.

7. Kebutuhan bayi adalah penggabungan dari makanan bayi dan keperluan bayi, seperti: sabun, sampo, bedak, minyak telon, makanan dan susu khusus untuk bayi.

8. Buah adalah buah-buahan yang dijual dan disimpan dalam rak biasa (bukan kulkas atau freezer)

9. Sembako merupakan Sembilan jenis kebutuhan pokok masyarakat menurut Keputusan Menteri Perindustrian dan Perdagangan Nomor 115/MPP/Kep/2/1998 tanggal 27 Februari 1998, dalam penelitian ini contohnya: minyak goreng, beras, telur, gula dan sebagainya.

10. Obat adalah suatu bahan yang dipergunakan dalam menetapkan mencegah, mengurangi, menghilangkan, menyembuhkan penyakit atau gejala penyakit.

11. Non konsumsi merupakan penggabungan dari jenis personal care, dan oral hygienic seperti sabun, sampo, pasta gigi dan lainnya. Serta house hold, house ware dan paper good seperti tas plastik, karbol, kamper, tisu, sikat, deterjen dan sebagainya.

\section{b. Eksplorasi Data}

Tabel 4. merupakan deskripsi statistik dari penjualan berdasarkan jumlah dari jenis item yang terjual, deskripsi statistik berguna untuk memperoleh bentuk nyata dari data sehingga lebih mudah dimengerti peneliti atau orang lain yang tertarik dengan hasil penelitian yang dilakukan (Irianto, 2010).

Dataset yang digunakan adalah data penjualan dalam satu tahun, terdapat sebanyak 36.574 transaksi untuk sekitar 1,2 juta jenis item yang terjual seperti rekapitulasi pada tabel 5. dibawah. Sedangkan gambar 1. adalah porsi dari penjualan berdasarkan jumlah item terjual.

TABEL 5

REKAPITULASI JUMLAH ITEM TERJUAL (Luky, 2021)

\begin{tabular}{|l|r|}
\hline \multicolumn{1}{|c|}{ Jenis Barang } & \multicolumn{1}{c|}{ Jumlah Terjual } \\
\hline Sembako & 917,980 \\
\hline Non Konsumsi & 280,725 \\
\hline Makanan Ringan & 25,479 \\
\hline Minuman & 23,637 \\
\hline Dry Food, Mie & 13,090 \\
\hline Frozen & 6,920 \\
\hline AMDK & 6,701 \\
\hline Bhn Minuman & 3,983 \\
\hline Obat & 2,188 \\
\hline Kbth Bayi & 872 \\
\hline Buah & 463 \\
\hline Total & $1,282,038$ \\
\hline
\end{tabular}

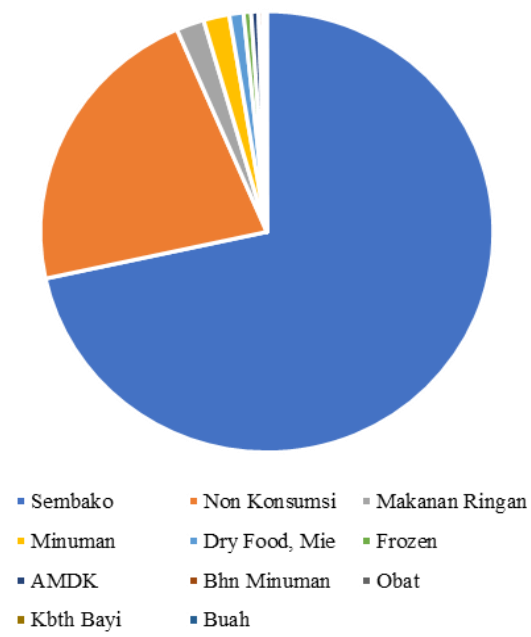

Gambar 1: Diagram Pie penjualan berdasarkan jumlah item (Luky, 2021) 
TABEL 4

DESKRIPSI STATISTIK JENIS BARANG (Luky, 2021)

\begin{tabular}{|c|c|c|c|c|c|c|c|}
\hline Jenis Barang & Mean & Median & Std Dev & Min & Max & Sum & Count \\
\hline Minuman & 1.771 & 1 & 2.088 & 1 & 101 & 23,637 & 13,345 \\
\hline Makanan Ringan & 2.044 & 1 & 2.127 & 1 & 50 & 25,479 & 12,465 \\
\hline Sembako & 86.545 & 2 & 283.818 & 1 & 4,031 & 917,980 & 10,607 \\
\hline Non Konsumsi & 27.541 & 1 & 420.288 & 1 & 9,999 & 280,725 & 10,193 \\
\hline Frozen & 1.836 & 1 & 1.604 & 1 & 45 & 6,920 & 3,770 \\
\hline Dry Food, Mie & 3.913 & 2 & 10.785 & 1 & 400 & 13,090 & 3,345 \\
\hline Bhn Minuman & 1.984 & 1 & 3.186 & 1 & 70 & 3,983 & 2,008 \\
\hline Obat & 1.532 & 1 & 1.287 & 1 & 16 & 2,188 & 1,428 \\
\hline Kbth Bayi & 1.543 & 1 & 1.555 & 1 & 19 & 872 & 565 \\
\hline AMDK & 14.107 & 2 & 32.117 & 1 & 384 & 6,701 & 475 \\
\hline Buah & 1.275 & 1 & 0.694 & 1 & 5 & 463 & 363 \\
\hline
\end{tabular}

TABEL 6

DATA PENJUALAN SEBELUM DILAKUKAN TRANSFORMASI (Luky, 2021)

\begin{tabular}{|c|c|c|c|c|c|c|c|c|}
\hline $\begin{array}{c}\text { No } \\
\text { Transaksi }\end{array}$ & AMDK & $\begin{array}{c}\text { Bhn } \\
\text { Minuman }\end{array}$ & $\begin{array}{c}\text { Dry } \\
\text { Food, } \\
\text { Mie }\end{array}$ & Frozen & $\begin{array}{c}\text { Makanan } \\
\text { Ringan }\end{array}$ & Minuman & $\begin{array}{c}\text { Non } \\
\text { Konsumsi }\end{array}$ & Sembako \\
\hline 1 & 0 & 0 & 0 & 0 & 5 & 7 & 0 & 0 \\
\hline 3 & 0 & 0 & 0 & 3 & 0 & 0 & 0 & 0 \\
\hline 4 & 0 & 0 & 0 & 0 & 7 & 7 & 3 & 9 \\
\hline 5 & 0 & 4 & 0 & 0 & 0 & 0 & 3 & 8 \\
\hline
\end{tabular}

TABEL 7

DATA PENJUALAN SETELAH DILAKUKAN TRANSFORMASI (Luky, 2021)

\begin{tabular}{|c|c|c|c|c|c|c|c|c|}
\hline $\begin{array}{c}\text { No } \\
\text { Transaksi }\end{array}$ & AMDK & $\begin{array}{c}\text { Bhn } \\
\text { Minuman }\end{array}$ & $\begin{array}{c}\text { Dry } \\
\text { Food, } \\
\text { Mie }\end{array}$ & Frozen & $\begin{array}{c}\text { Makanan } \\
\text { Ringan }\end{array}$ & Minuman & $\begin{array}{c}\text { Non } \\
\text { Konsumsi }\end{array}$ & Sembako \\
\hline 1 & 0 & 0 & 0 & 0 & 1 & 1 & 0 & 0 \\
\hline 3 & 0 & 0 & 0 & 1 & 0 & 0 & 0 & 0 \\
\hline 4 & 0 & 0 & 0 & 0 & 1 & 1 & 1 & 1 \\
\hline 5 & 0 & 1 & 0 & 0 & 0 & 0 & 1 & 1 \\
\hline
\end{tabular}




\section{c. Transformasi Data}

Untuk mencari aturan asosiasi atau analisis keranjang belanja yang dibutuhkan adalah data penjualan berdasarkan jenisnya saja (count), contohnya dalam satu transaksi terdapat pembelian tiga cup es krim, namun hanya dihitung satu es krim saja. Dengan demikian diperlukan transformasi data atau binerisasi terhadap data, dengan kata lain tipe data diubah kedalam bentuk biner (Werdiningsih et al., 2020) seperti contoh pada tabel 6. dan tabel 7. disajikan tabulasi sebelum dan sesudah dilakukan transformasi.

Dari data penjualan terdapat 58.564 barang berdasarkan jenis item terjual, tabel. 8 adalah rekapitulasi jumlah per jenis item/barang terjual dan gambar 2. merupakan porsi dari penjualan berdasarkan jenis item terjual.

TABEL 8

REKAPITULASI ITEM TERJUAL BERDASARKAN JENIS (Luky,

\begin{tabular}{|l|r|}
\hline \multicolumn{1}{|c|}{ Jenis Barang } & \multicolumn{1}{c|}{ Jumlah per Jenis } \\
\hline Minuman & 13,345 \\
\hline Makanan Ringan & 12,465 \\
\hline Sembako & 10,607 \\
\hline Non Konsumsi & 10,193 \\
\hline Frozen & 3,770 \\
\hline Dry Food, Mie & 3,345 \\
\hline Bhn Minuman & 2,008 \\
\hline Obat & 1,428 \\
\hline Kbth Bayi & 565 \\
\hline AMDK & 475 \\
\hline Buah & 363 \\
\hline Total & 58,564 \\
\hline
\end{tabular}

\section{d. Hari Besar Islam}

Minimarket dalam penelitian ini merupakan bagian dari Koperasi yang dimiliki dan dikelola oleh komunitas muslim yang berdomisili di area Kota Depok, Jawa Barat, lebih tepatnya kecamatan Cimanggis dan sekitarnya, oleh sebab itu dalam penelitian ini bertujuan mendapatkan aturan asosiasi dari jenis item yang terjual pada event tertentu yang berhubungan dengan hari besar agama Islam, dikarenakan pada event tertentu biasanya dilakukan charity, santunan dan kegiatan social lainnya.

Adapun hari besar Islam yang dimaksud adalah sebagai berikut:

1. Bulan Romadhon dan Idul Fitri, data yang dipakai diambil dari tiga hari sebelum bulan Romadhon hingga tiga hari setelah Idul Fitri.

2. Idul Adha, data dipakai adalah data penjualan pada hari tersebut.

3. Maulid Nabi Muhammad SAW, data dipakai adalah data penjualan pada hari tersebut.

4. Tahun Baru Islam, data dipakai adalah data penjualan pada hari tersebut.

\section{e. Aturan Asosiasi}

Berdasarkan jumlah keseluruhan transaksi dan jumlah jenis item yang terjual, seperti terdapat pada Tabel 8., maka threshold $(\theta)$ yang digunakan dalam penelitian ini sebesar $30 \%$, yang artinya hanya aturan yang memiliki nilai confidence $\geq 30 \%$ saja yang diambil. Penelitian menggunakan tools atau bantuan software Weka versi 3.8.4, hasil yang didapat direkapitulasi pada tabel 9. Dibawah ini.

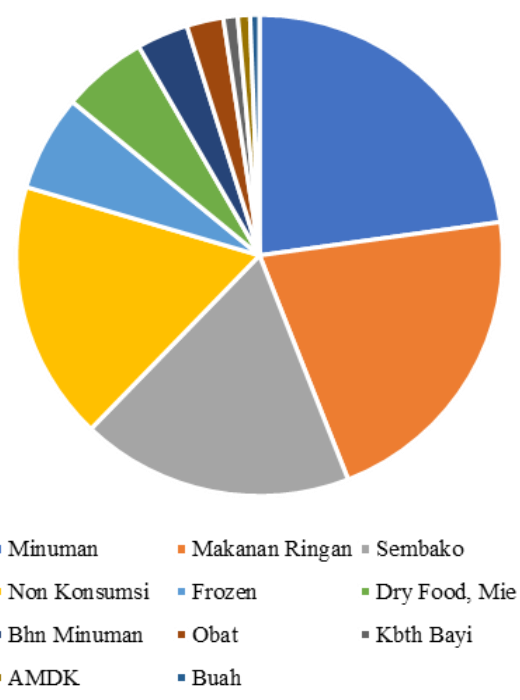

Gambar 2: Diagram Pie porsi penjualan berdasarkan jumlah item berdasarkan jenis (Luky, 2021) 
TABEL 9

REKAPITULASI HASIL PERHITUNGAN UNTUK MENDAPATKAN ATURAN ASOSIASI (Luky, 2021)

\begin{tabular}{|c|c|c|c|c|c|c|c|c|}
\hline Event & $\begin{array}{l}\text { Jumlah } \\
\text { Transaksi }\end{array}$ & \multicolumn{2}{|c|}{$\begin{array}{l}\text { Jumlah } 1 \text { item terjual yang } \\
\text { memiliki frekuensi tinggi }\end{array}$} & \multicolumn{4}{|c|}{$\begin{array}{l}\text { Jumlah } 2 \text { itemset terjual bersamaan yang memiliki } \\
\text { frekuensi tinggi }\end{array}$} & $\begin{array}{l}\text { Nilai } \\
\text { Confidence } \\
\text { Aturan }\end{array}$ \\
\hline \multirow{5}{*}{$\begin{array}{l}\text { Semua } \\
\text { Transaksi }\end{array}$} & \multirow{5}{*}{36,575} & Minuman & 13,345 & $\begin{array}{l}\text { Makanan } \\
\text { Ringan }\end{array}$ & » & Minuman & 4,119 & $33 \%$ \\
\hline & & $\begin{array}{l}\text { Makanan } \\
\text { Ringan }\end{array}$ & 12,465 & $\begin{array}{l}\text { Makanan } \\
\text { Ringan }\end{array}$ & " & Sembako & 3,679 & $35 \%$ \\
\hline & & Sembako & 10,607 & & & & & \\
\hline & & $\begin{array}{l}\text { Non } \\
\text { Konsumsi }\end{array}$ & 10,193 & & & & & \\
\hline & & Frozen & 3,770 & & & & & \\
\hline \multirow{7}{*}{$\begin{array}{l}\text { Bulan } \\
\text { Ramadan }\end{array}$} & \multirow{7}{*}{2,077} & Sembako & 871 & $\begin{array}{l}\text { Makanan } \\
\text { Ringan }\end{array}$ & » & Sembako & 329 & $46 \%$ \\
\hline & & $\begin{array}{l}\text { Non } \\
\text { Konsumsi }\end{array}$ & 777 & Non Konsumsi & 》 & Sembako & 305 & $39 \%$ \\
\hline & & $\begin{array}{l}\text { Makanan } \\
\text { Ringan }\end{array}$ & 708 & $\begin{array}{l}\text { Makanan } \\
\text { Ringan }\end{array}$ & 》 & Minuman & 258 & $39 \%$ \\
\hline & & Minuman & 668 & Minuman & » & Sembako & 236 & $35 \%$ \\
\hline & & $\begin{array}{ll}\text { Dry } & \text { Food, } \\
\text { Mie } & \\
\end{array}$ & 245 & $\begin{array}{l}\text { Makanan } \\
\text { Ringan }\end{array}$ & » & $\begin{array}{l}\text { Non } \\
\text { Konsumsi }\end{array}$ & 228 & $32 \%$ \\
\hline & & $\begin{array}{l}\text { Bhn } \\
\text { Minuman }\end{array}$ & 243 & & & & & \\
\hline & & Frozen & 238 & & & & & \\
\hline \multirow{6}{*}{ Idul Adha } & \multirow{6}{*}{257} & Sembako & 103 & Non Konsumsi & » & Sembako & 31 & $42 \%$ \\
\hline & & Minuman & 90 & $\begin{array}{l}\text { Makanan } \\
\text { Ringan }\end{array}$ & » & Sembako & 28 & $43 \%$ \\
\hline & & $\begin{array}{l}\text { Non } \\
\text { Konsumsi } \\
\end{array}$ & 74 & & & & & \\
\hline & & $\begin{array}{l}\text { Makanan } \\
\text { Ringan }\end{array}$ & 65 & & & & & \\
\hline & & Frozen & 35 & & & & & \\
\hline & & $\begin{array}{l}\text { Dry Food, } \\
\text { Mie }\end{array}$ & 29 & & & & & \\
\hline \multirow{4}{*}{$\begin{array}{l}\text { Maulid } \\
\text { Nabi }\end{array}$} & \multirow{4}{*}{219} & Minuman & 90 & $\begin{array}{l}\text { Makanan } \\
\text { Ringan }\end{array}$ & » & Minuman & 30 & $38 \%$ \\
\hline & & $\begin{array}{l}\text { Makanan } \\
\text { Ringan }\end{array}$ & 78 & $\begin{array}{l}\text { Makanan } \\
\text { Ringan }\end{array}$ & 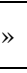 & Sembako & 28 & $36 \%$ \\
\hline & & Sembako & 73 & & & & & \\
\hline & & $\begin{array}{l}\text { Non } \\
\text { Konsumsi }\end{array}$ & 45 & & & & & \\
\hline \multirow{5}{*}{$\begin{array}{l}\text { Tahun Baru } \\
\text { Islam }\end{array}$} & \multirow{5}{*}{203} & Minuman & 88 & $\begin{array}{l}\text { Makanan } \\
\text { Ringan }\end{array}$ & 》 & Minuman & 26 & $42 \%$ \\
\hline & & $\begin{array}{l}\text { Makanan } \\
\text { Ringan }\end{array}$ & 62 & Non Konsumsi & 》 & Sembako & 24 & $41 \%$ \\
\hline & & Sembako & 62 & Minuman & 》 & Sembako & 22 & $35 \%$ \\
\hline & & $\begin{array}{l}\text { Non } \\
\text { Konsumsi }\end{array}$ & 58 & & & & & \\
\hline & & Frozen & 21 & & & & & \\
\hline
\end{tabular}




\section{Kesimpulan}

Metode Aturan asosiasi dengan menggunakan algoritma A Priori cukup tepat untuk menghasilkan pola aturan hubungan antar jenis item yang terjual, nilai support pada frequent item dan confidence pada rules yang didapat bisa memberikan wawasan yang dapat ditindaklanjuti oleh pengelola toko, minimarket, koperasi dan sebagainya. Terutama ketersediaan stok dalam menghadapi hari besar yang dimaksud.

Dengan kategorisasi jenis item yang cukup banyak dan jumlah keseluruhan transaksi yang sangat banyak serta penjualan berdasarkan jenis barang dalam satu transaksi yang tidak cukup banyak maka nilai threshold tidak terlalu baik jika terlalu tinggi. Pada penelitian selanjutnya dapat diperketat dengan mengeleminasi transaksi-transaksi yang tidak memiliki jumlah jenis itemset terjual yang tidak banyak.

Penelitian ini dapat dijadikan model untuk diterapkan pada koperasi atau toko modern yang dimiliki oleh komunitas lain yang tentunya juga memiliki event tertentu yang sesuai,

\section{Daftar Pustaka}

A. Aishwarya, B. R. (2016). A LITERATURE STUDY ON APPLICATION OF DATA MINING TOOLS FOR RICE YIELD PREDICTION. International Journal of Innovative Technology and Research, 4(1), 2757-2759. https://www.ijitr.com/index.php/ojs/article/vi ew/791

B. Edward, N., Intan, R., \& Infra, A. T. (2019). Analisis Consumer Behaviour Pada Toko Retail Dengan Metode APRIORI-SD. Jurnal Infra, $7(2)$, 185-189. http://publication.petra.ac.id/index.php/tekni k-informatika/article/download/8829/7972

C. Irianto, A. (2010). Statistik Konsep Dasar, Aplikasi, dan Pengembangannya. Prenada Media Group.

D. Kaur, M., \& Kang, S. (2016). Market Basket
Analysis: Identify the changing trends of market data using association rule mining. Prodecia Computer Science, 85, 78-85. https://www.sciencedirect.com/science/articl e/pii/S1877050916305208

E. Shelke, R. R., Dharaskar, R. V., \& Thakare, V. M. (2017). Data mining for supermarket sale analysis using association rule. International Journal of Trend in Scientific Research and Development, 1(4). https://www.academia.edu/download/539988 95/22_Data_Mining_For_Supermarket_Sale _Analysis_Using_Association_Rule.pdf

F. Sujana, A. S. (2005). Paradigma Baru Dalam Manajemen Ritel Modern. Graha Ilmu.

G. Werdiningsih, I., Nuqoba, B., \& Muhammadun, S. S. (2020). Data Mining Menggunakan Android, Weka, dan SPSS. Airlangga University Press.

H. Wijaya, K. N. (2017). Analisa Pola Frekuensi Keranjang Belanja Dengan Algoritma Apriori (Studi kasus: Minimarket Adi). Annual Research Seminar (ARS), 3(1), 9-12. http://seminar.ilkom.unsri.ac.id/index.php/ars /article/view/1707 